\title{
Analysing the Behaviour of Copper Oxide- Thermal Oil on Forced Convection and Pressure Drop in Upward and Downward Flow in Plain and Microfin Tube
}

ISSN: 2576-8840

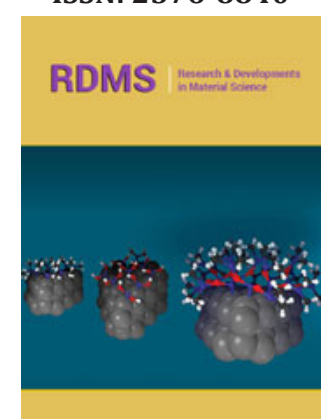

*Corresponding author: Vikash Agrawal, School of Physics, Southeast University, China

Farhad Hekmatipour, Department of Natural sciences, Don State Technical University, Russia

Submission: 㘹 April 05, 2021

Published: 㠿April 20, 2021

Volume 15 - Issue 1

How to cite this article: Milad Jalali, Farhad Hekmatipour, Vikash Agrawal. Analysing the Behaviour of Copper OxideThermal Oil on Forced Convection and Pressure Drop in Upward and Downward Flow in Plain and Microfin Tube. Res Dev Material Sci. 15(1). RDMS.000854. 2021. DOI: 10.31031/RDMS.2021.15.000854

Copyright@ Farhad Hekmatipour, Vikash Agrawal. This article is distributed under the terms of the Creative Commons Attribution 4.0 International License, which permits unrestricted use and redistribution provided that the original author and source are credited.

\author{
Milad Jalali ${ }^{1}$, Farhad Hekmatipour ${ }^{2 *}$ and Vikash Agrawal ${ }^{1 *}$ \\ ${ }^{1}$ School of Physics, Southeast University, China
}

${ }^{2}$ International faculty DSTU, Department of Natural sciences, Don State Technical University, Russia

\begin{abstract}
The effects of using copper oxide-thermal oil on convective heat transfer and pressure drop in a downward flow in an inclined microfin tube are investigated experimentally in this research project. The flow regime and wall temperature are laminar and constant, respectively. The effects of nanofluid, Graetz number, Prandtl number, negative and positive inclination angles, on convective heat transfer augment moderately as nanoparticles mass concentration increases. Correlations are advisable to anticipate Nusselt number and Darcy friction factor in upward and downward single-phase flow in microfin tube under constant wall temperature and laminar flow in inclined plain and finned tubes. The maximum aberration is lower than $21 \%$ which is acceptable to predict experimental data. In this paper, we found that the heat ratio matches the pumping ratio. It turns out that, if the increment of pressure drop is more than heat transfer enhancement, it will not be appropriate to use CuO-thermal oil, negative inclination angles and microfin tube. The maximum FOM was $64 \%$, which, was calculated with $1.5 \%$ nanoparticles mass concentration and inclination angle $60^{\circ}$ at Prandtl number 349 in microfin tube.
\end{abstract}

Keywords: Nanofluid; Pressure drop; Convective heat transfer; Upward and downward flow; Friction factor; Laminar flow

\section{Introduction}

The improvement of thermal conductivity and convective heat transfer can be influential on the declination of heat losses and fuel consumption in heat exchangers in industrial applications such as microelectronics, petrochemical, oil and gas, and airconditioning. Indeed, if advanced methods are applied to improve convective heat transfer, the greenhouse gases emitted by manufacturers and buildings will decrease dramatically in the future. Therefore, we can prevent or at least hinder global warming. Over the last 100 years of investigation, several mechanicalmethods have been applied to enhance convective heat transfer in inclined tubes. The prediction of mixed convection heat transfers in vertical [1-3], horizontal [4-6] and inclinedtubes [7-9]. It is reported that the inclination angle may be effective on the enhancement of combined free and natural convection heat transfer in inclined tubes [1-3,7-9]. It is shown that mixed convection heat transfer augments with the increase in inclination angle and the best results can be achieved at an angle of $60^{\circ}$ [7].

Due to the low thermal conductivity of normal fluids, e.g., water, glycol solution, and oil; themain convection heat transfer and Nusselt number are shown to be really low. It is acceptableto add nanoparticles to the based fluid since nanoparticles help to improve the efficacy of fluids. Indeed, the thermal-rheological properties of fluid may enhance significantly when nanoparticles are added to the base fluids. During the three last decades, most of the investigations were focused on improvement of thermal conductivity and convective heat transfer of nanofluids in different tubes [10-21]. It is obvious that the application of nanofluids as working fluids is useful in industrial applications since the use of nanofluids can be influential on the enhancement of thermal conductivity. Since the augmentation of thermal conductivity affects the improvement of convection heat transfer, it can reduce the heat losses in heat exchangers in cooling and heating systems [1021]. According to the thermalrheological properties of nanofluids, many researchers 
have applied nanofluids to determinethe amount of convective heat transfer and the behaviour of nanofluids in different circumstances as predicted. Most of these researchers used nanofluid sand mechanical methods such as twisted tapes [22$25]$, helical tubes [26-28], microfin tubes [29,30], and annulus tubes $[31,32]$. The results of these investigations showed that the convective heat transfer improvessubstantially when mechanical methods and nanofluids are applied. It can be seen that twisted tape is more effective than other mechanical methods due to intensified creation of vortex flow in the tube and the declination of the boundary layer [22-25]. Despite, a dramatic increase in pressure drops and Darcy friction factor, when it is used twisted tapes and nanofluid are observed.

These studies continue to determine the effect of using a nanofluid and inclined tube on the improvement of mixed convection heat transfer after nanofluids were introduced as working fluid in different studies [33-37]. The results of investigations illustrated that heat transfer canbe improved by adding nanoparticles to the base fluid and inclination angles. It was reported that maximum mixed convection heat transfer occurs at an angle of $30^{\circ}$ and $60^{\circ}$ [33,34]. It isalso mentioned that reverse flow can be effective on the augmentation of heat transfer in inclined tubes [33-39].

The forced convection heat transfer is used in industrial applications since the use of mixed convection heat transfer is not economical. To determine the influence of adding nanoparticlet base fluid and positive inclination angles on forced convection in inclined plain and microfin tubes, this research is done to obtain new correlations which are capable of predicting Darcyfriction factor and forced convection heat transfer in inclined tubes. The wall temperature of the pipe is stable, and the flow rate is low enough to certify that the flow regime stays laminar.

\section{Experimental Implementation}

\section{Nanofluid characteristics}

In this experimental research, the average size of $\mathrm{CuO}$ nanoparticles and purity are 40nm and 99\%, respectively. SEM (Scanning Electron Microscope) image of the nanoparticles is depicted in Figure 1. The shape of copper oxide nanoparticles was irregular. An ultrasonic UPS400 machine with a frequency of $24 \mathrm{kHz}$ and the power of $400 \mathrm{~W}$ was applied to make a homogeneous product and a relatively stable nanofluid. The procurement of several thermaloil- copper oxide nanoparticle suspensions with the weight concentrations of $0.5 \%, 1 \%$, and $1.5 \%$ was performed using a precise laboratory measurement. The nanofluids were fixed for 216 hours, the nanoparticles sedimentation started from $216 \mathrm{hr}$ and these particles were settled down totally for 14 days. Thermo-physical characteristics of the thermal oil and copper oxidenanoparticles are shown in Tables $1 \& 2$, respectively. Akhavan-Behabadi et al. [40] have described the thermophysical characteristics of nanofluids utilized in this paper.

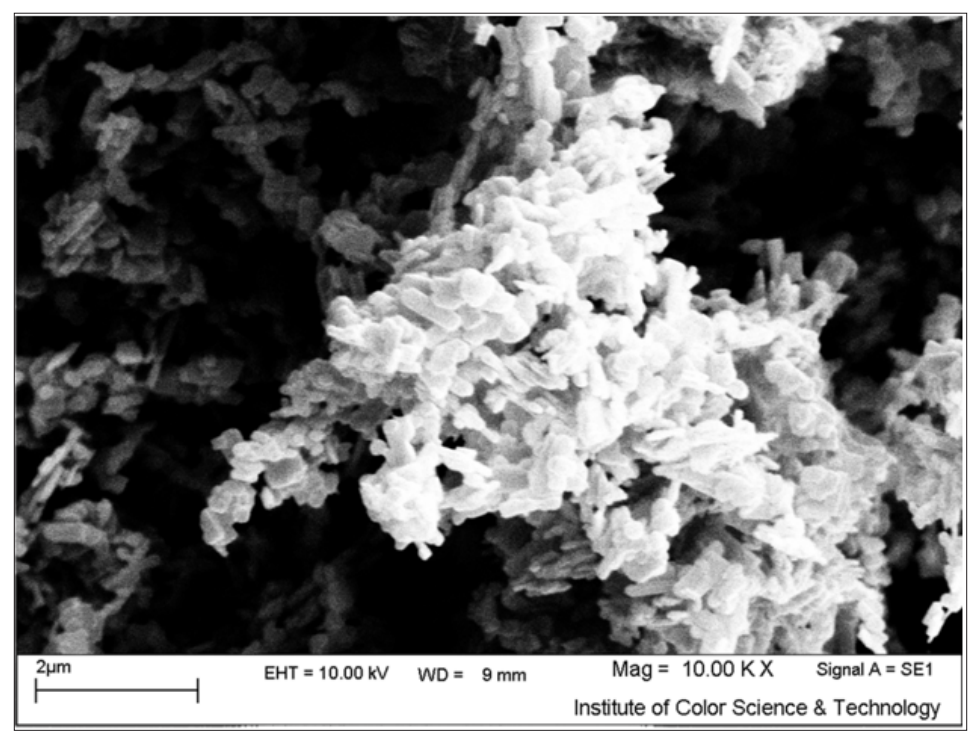

Figure 1: SEM image of the copper oxide nanoparticles.

\section{Experimental facilities}

To perform the measurements of convective heat transfer and pressure drop of nanofluids, theassemblage of the experimental facility was set up and a schematic image of the experimental facility is presented in Figure 2. The circulation of flow has a different part including a test tube, pre-cooler, storage tank, heat exchanger, gear pump, flow meter, differential manometer, thermocouples, and flow control systems. The specification of tubes and the characteristics of nanofluids utilized in the experimental analysis are mentioned in Tables $1 \& 2$. In the experimental analysis, inclined, smooth and microfin pipes were employed and the comparison between the two kinds is pointed in Table 3. The gap time needed for the flow to change to steadystate was approximately 15 minutes and the gap time required for noting experimentaldata was 30 minutes. 
Table 1: Thermo-physical characteristics of the Heat Transfer Oil (HTO).

\begin{tabular}{|c|c|c|}
\hline \multirow{2}{*}{ Thermo-Physical Property } & \multicolumn{2}{|c|}{ Temperature $\left({ }^{\circ} \mathbf{C}\right)$} \\
\cline { 2 - 3 } & 38 & 100 \\
\hline$\rho\left(\mathrm{kg} / \mathrm{m}^{3}\right)$ & 855 & 815 \\
\hline $\mathrm{Cp}(\mathrm{kJ} / \mathrm{kg} . \mathrm{K})$ & 2.03 & 2.3 \\
\hline$\vartheta\left(\mathrm{m}^{2} / \mathrm{s}\right)$ & $32 \times 10^{-6}$ & $5.2 \times 10^{-6}$ \\
\hline $\mathrm{k}(\mathrm{W} / \mathrm{m} . \mathrm{K})$ & 0.133 & 0.128 \\
\hline Prandtl number & 395 & 76 \\
\hline
\end{tabular}

Table 2: Thermo-physical characteristics of $\mathrm{CuO}$ nanoparticles.

\begin{tabular}{|c|c|}
\hline Thermo-physical property & Value \\
\hline Morphology & Nearly irregular shapes \\
\hline Particle size $(\mathrm{nm})$ & 40 \\
\hline Purity $(\%)$ & 99 \\
\hline Bulk density $\left(\mathrm{kg} / \mathrm{m}^{3}\right)$ & 790 \\
\hline
\end{tabular}

\begin{tabular}{|c|c|}
\hline True density $\left(\mathrm{kg} / \mathrm{m}^{3}\right)$ & 6400 \\
\hline $\operatorname{SSA}\left(\mathrm{m}^{2} / \mathrm{g}\right)$ & 20 \\
\hline Thermal conductivity $(\mathrm{W} / \mathrm{m} . \mathrm{K})$ & 20 \\
\hline
\end{tabular}

Table 3: Specification of the circular and microfin pipes.

\begin{tabular}{|c|c|c|}
\hline Parameter & $\begin{array}{c}\text { Dimension Circu- } \\
\text { lar Pipe }\end{array}$ & $\begin{array}{c}\text { Dimension Microfin } \\
\text { Pipe }\end{array}$ \\
\hline $\begin{array}{c}\text { Pipe inner/outer diame- } \\
\text { ter }(\mathrm{mm})\end{array}$ & $8.95 / 9.52$ & $8.62 / 9.52$ \\
\hline Pipe length $(\mathrm{mm})$ & 500 & 500 \\
\hline Pipe thickness $(\mathrm{mm})$ & 0.42 & 0.45 \\
\hline Fin height $(\mathrm{z})(\mathrm{mm})$ & --- & 0.2 \\
\hline Fin pitch $(\mathrm{mm})$ & --- & 0.45 \\
\hline Number of fins $(\mathrm{N})$ & --- & 60 \\
\hline Helix angle $(\gamma)$ & --- & 18 \\
\hline Vertex angle $(\tau)$ & --- & 24 \\
\hline
\end{tabular}

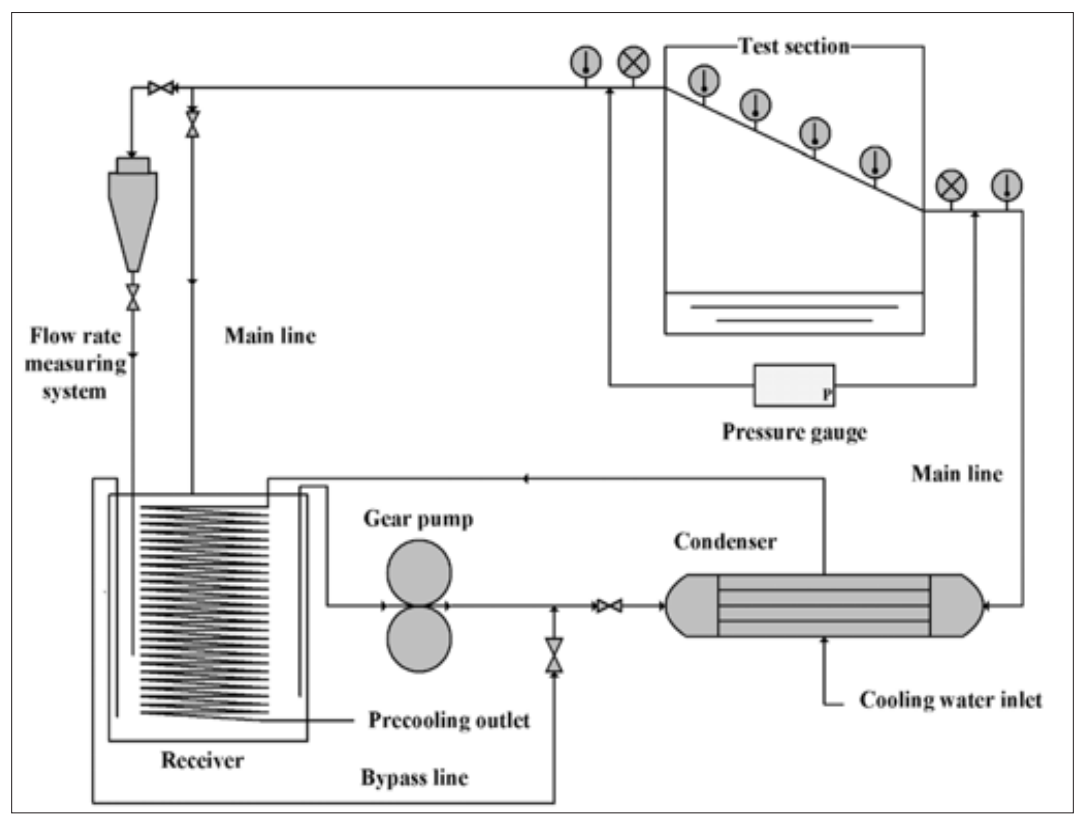

Figure 2: Schematic of the test setup.

The test tube is located in a steam tank that holds pipe wall temperature at $98 \stackrel{\circ}{\circ}$. The glass- fiber insulation was applied to decrease the heat losses from the steam tank. Two stages were embedded to cool down the nanofluids. Initially, cooling water and a copper coil embedded in storage tank were used to decrease the temperature of nanofluids. To reduce the temperature of nanofluid flow, the shell and tube heat exchanger were utilized to reach $15 \stackrel{\circ}{\circ} \mathrm{C}$ temperature. By use of gear pump, cool nanofluid in the storage tank was circulated throughout the mainline. The gear pump use to produce a constant velocity. To adjust the flow rate in the mainline, abypass line was embedded to alter the flow rate. Change of flow rate was done using a globevalve and some of the flow was strayed into the storage tank. The flow rate was kept always in the laminar regime. In the test section, four thermocouples were joined at specified intervals to measure the tube-wall temperature. Besides, two thermocouples were fitted inside and outsideof the test section to measure the temperatures inside and outside of the surface.

\section{Instruments}

The measurement of the nanofluid temperature in the test section inlet and outlet was made by using two RTD PT 100 adhered to thermometers which were utilized with the accuracy of $\pm 0.1{ }^{\circ} \mathrm{C}$. The assemblage of the RTD sensors was done to sense the center temperature of thefluid at the inlet and outlet temperature. The position of four K-type thermocouples with theSU-105 KPR sensor had 100mm intervals T1 (100mm), T2 (200mm), T3 (300mm), and T4 (400mm) to measure the 
temperature of wall tubes. The thermocouples were welded on theouter wall tubes to prevent the effects of steam and nanofluid on thermocouples.

The preliminary calculations showed that due to the low thermal resistance of the copper tube wall compared to the convective one, the temperature gradient in the tube wall is negligible.The temperature of $\mathrm{T} 1$, to $\mathrm{T} 4$ are 98.1, 97.8, 98.0, and 98.1, respectively, which shows that the tube wall temperature is almost constant.

The measurement of pressure drop was done by using A PMD75 pressure transmitter with an accuracy of $\pm 0.075 \%$. The flow rate was measured by a $1000 \mathrm{ml}$ scaled separation funnel. The measurement of flow rate was done with the filling funnel time and by using a digital timer with an accuracy of 0.01s. Measuring analytic uncertainty of convective heat transfer and pressure drop was done according to the method of uncertainty in experimental results $[41,42]$ and it was obtained,using the data in Table 4. Accordingly, the maximum aberration of the mean convective heat transfer coefficient, the Nusselt number and the figure of merit were $6.8 \%, 6.5 \%$, and $6.7 \%$ respectively. The formulation used to measure analytical uncertainty is presented in the Appendix.

Table 4: Specification of the instruments.

\begin{tabular}{|c|c|c|c|}
\hline Property & Instrument & Range & Accuracy \\
\hline Inlet/outlet temperature & RTD PT 100 & -200 to $400{ }^{\circ} \mathrm{C}$ & $\pm 0.1^{\circ} \mathrm{C}$ \\
\hline Pipe wall temperature & K-type thermocouple & -200 to $999^{\circ} \mathrm{C}$ & $\pm 0.1{ }^{\circ} \mathrm{C}$ \\
\hline Flow rate & Separation funnel & 0 to 11 & $\pm 100 \mathrm{ml}$ \\
\hline Pressure drop & PMD-75 & 10 mbar to 40 bar & \pm 0.075 \\
\hline
\end{tabular}

\section{Appendix}

Based on Holman [32,33], if the parameter R depends on variables V1 to Vn which can be gauged with an uncertainty of UV1 to UVn, the overall uncertainty of $\mathrm{R}$ is:

$$
U_{R}=\left[\sum_{i=1}^{n}\left(\frac{\partial R}{\partial V_{i}} U_{V_{i}}\right)^{2}\right]^{1 / 2}
$$

Based on the definition of Darcy friction factor, Eq. (1):

$$
U_{f}=\left[\left(\frac{\pi^{2} D^{5}}{L \rho \dot{Q}^{3}} \Delta p U_{\dot{Q}}\right)^{2}+\left(\frac{\pi^{2} D^{5}}{L \rho \dot{Q}^{2}} U_{\Delta p}\right)^{2}+\left(\frac{\pi^{2} D^{5}}{L \rho^{2} \dot{Q}^{2}} \Delta p U_{\rho}\right)^{2}\right]^{1 / 2}
$$

Moreover, for the Nusselt number, Eq. (2):

$$
\begin{aligned}
U_{N u}=\left\{\left[\frac{\rho c_{p}}{\pi L k}\right.\right. & \left.\ln \left(\frac{T_{w}-T_{b, i}}{T_{w}-T_{b, o}}\right) U_{\dot{Q}}\right]^{2}+\left[\frac{\rho c_{p} \dot{Q}}{\pi L k} \frac{T_{b, o}-T_{b, i}}{\left(T_{w}-T_{b, i}\right)\left(T_{w}-T_{b, o}\right)} U_{T_{w}}\right]^{2} \\
& +\left[\frac{\rho c_{p} \dot{Q}}{\pi L k} \frac{1}{T_{w}-T_{b, i}} U_{T_{b, i}}\right]^{2}+\left[\frac{\rho c_{p} \dot{Q}}{\pi L k} \frac{1}{T_{w}-T_{b, o}} U_{T_{b . o}}\right]^{2} \\
& \left.+\left[\frac{c_{p} \dot{Q}}{\pi L k} \ln \left(\frac{T_{w}-T_{b, i}}{T_{w}-T_{b, o}}\right) U_{\rho}\right]^{2}+\left[\frac{\rho \dot{Q}}{\pi L k} \ln \left(\frac{T_{w}-T_{b, i}}{T_{w}-T_{b, o}}\right) U_{c_{p}}\right]^{2}\right\}^{1 / 2}
\end{aligned}
$$

From the definition of the performance index, Eq. (8), it can be concluded that:

$$
\begin{gathered}
U_{F O M}=\left[\left(\frac{1 / h_{b_{f}}}{\Omega_{n_{f}} / \Omega_{b_{f}}} U_{h_{n_{f}}}\right)^{2}+\left(\frac{h_{n_{f}} / h_{b_{f}}^{2}}{\Omega_{n_{f}} / \Omega_{b_{f}}} U_{h_{b_{f}}}\right)^{2}+\left(\frac{h_{n_{f}} / h_{b_{f}}}{\Omega_{n_{f}}^{2} / \Omega_{b_{f}}} U_{\Omega_{n_{f}}}\right)^{2}\right. \\
\left.+\left(\frac{h_{n_{f}} / h_{b_{f}}}{\Omega_{n_{f}}} U_{\Omega_{n_{f}}}\right)^{2}\right]^{1 / 2}
\end{gathered}
$$




\section{Result and Discussion}

The estimation of the heat transfer coefficient of nanofluid flow and pressure drop iscalculated as follows, respectively:

$$
\begin{gathered}
\mathrm{Nu}_{\text {exp }}=\frac{\dot{\mathrm{m}} \mathrm{C}_{\mathrm{p}}}{\pi \mathrm{Lk}} \ln \left(\frac{\mathrm{T}_{\mathrm{w}}-\mathrm{T}_{\mathrm{b}, \mathrm{i}}}{\mathrm{T}_{\mathrm{w}}-\mathrm{T}_{\mathrm{b}, \mathrm{o}}}\right) \\
\mathrm{f}_{\mathrm{exp}}=\frac{\pi^{2} \rho \mathrm{D}^{5}}{2 \mathrm{~L} \dot{m}^{2}} \Delta \mathrm{P}
\end{gathered}
$$

The calculation of the microfin hydraulic diameter tube is done [43] using the following rule:

$$
D_{h}=\frac{2 R}{\left(\left(\frac{N h}{\pi}\right)+1\right)}
$$

Due to the anticipation of experiments and the acquisition of inaccurate Darcy friction factor and convective heat transfer Nusselt number of thermal oil in the horizontal circular pipe, a comparison between experiments' outcome and prediction of Sider-Tate [44] and Hagen- Poiseuile [45] models, respectively has been provided. Figure 3 shows the contrast between empirical data and prediction numerical models. The difference (disagreement) between empirical data and the prediction of heat transfer and pressure drop models are approximately $13 \%$ and $11 \%$, respectively. The aberration of empirical data and classical models are suitable.

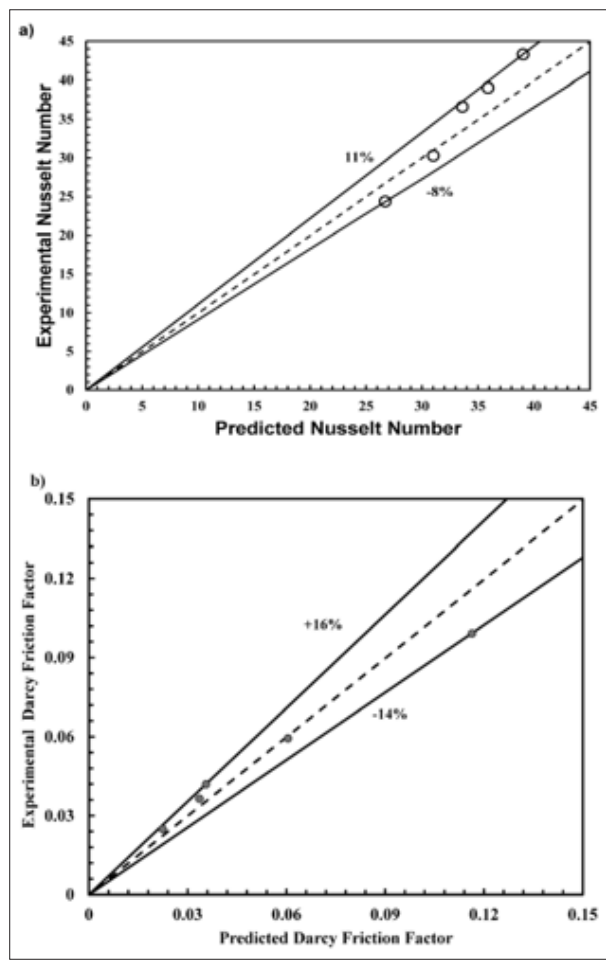

Figure 3: Comparison of the experimental data with the classic equations: (a) Nusselt number Darcy; (b) friction factor.

\section{Pressure drop}

Plain tube: Hydraulic development-length which is extremely effective on the shape of flow and flow regime is acquired from $L_{\mathrm{e}}<0.058 R e_{\mathrm{d}^{*}} d$. The maximum hydraulic development length is $0.399 \mathrm{~m}$. The results for Darcy friction factor of copper oxidethermal oil nanofluid flow in upward and downward flow in the inclined plain tube is plotted in Figure 4. The increment of Graetz number, nanoparticle mass concentration and inclination angle can be influential on the growth of Darcy friction factor. The declination of the boundary layer and surge in Darcy friction factor is due to nanoparticles' Brownian motion and formation of vortex flow in inclined plain tube. Another reason is the expansion of velocity profile and wall stress sharing. The influence of changing density and the increment of mass concentration on the improvementof heat transfer is accepted. Therefore, the increment of Darcy friction factor ratio is calculated to be approximately $48 \%$. The lack of classical correlation causes the inability to anticipate the result of Darcy friction factor of nanofluid in inclined plain tube. To predict the influence of using nanofluid and positive inclination angle on Darcy friction factor in a plain tube, a new correlation is introduced based on empirical information which is acquired from experiments.Indeed, most of the correlations are presented based on Rayleigh number and Richardson number; although, this equation is obtained based on Graetz number. This is because it is popular to use forced convection in industrial usages. The advisable correlation is demonstrated to estimate the friction factor of copper oxide-thermal oil flow in an inclined plain tube. It is as follows:

$$
\frac{f_{n_{f}}}{f_{b_{f}}}=0.4(1+\cos \theta)^{0.1}(1+\varphi)^{0.3}\left(1+G z^{0.1}\right)^{0.7}\left(\frac{\mu_{n_{f}}}{\mu_{b_{f}}}\right)^{0.14}
$$




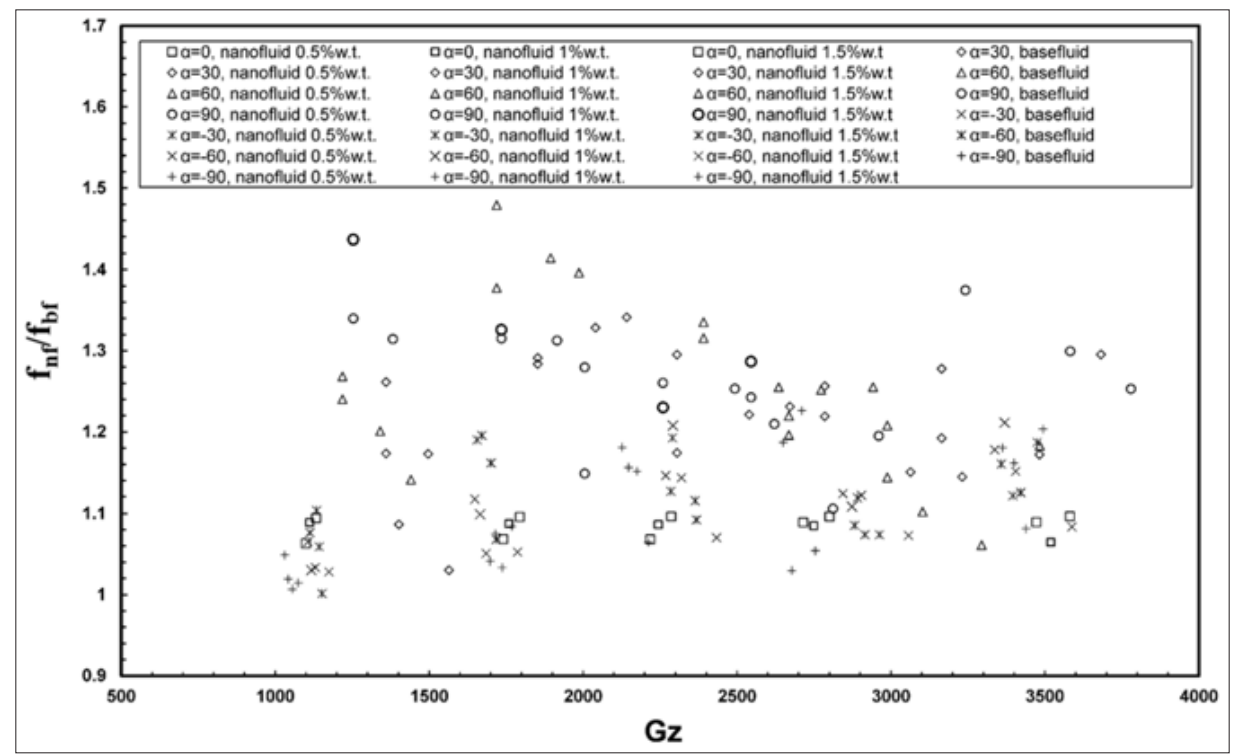

Figure 4: The influence of using $\mathrm{CuO}$ nanoparticles on the Darcy friction factor of the nanofluid flow in the inclined plain pipes based on the Darcy friction factor $(a=270,330300,0,30,60,90)$.

The equation evaluates for $0<\varphi<1.5 \%, 0<\theta<90$ \& $270<\theta<0, \quad 200<R e<800, \quad 320<P r_{\text {nf }}<402, \quad 1080<G z<3600$. The terms, positive inclination angle, nanoparticle mass concentration, Reynolds number, dynamic viscosity ratio is acquired by Darcy friction factor of copper oxide-thermal oil nanofluid. The comparison between experimental results and predicted results based on Eq. 4 is presented in Figure 5. It is seen that the maximum deflection of experimental results is almost $20 \%$. Thus, the advisable equation can be used for anticipation of experimental Darcy friction factor. This useful correlation can be useful because of nanoparticles' mass concentration. Graetz number, positive inclination angle, and dynamic viscosity ratio are applied to introduce an equation. The classical correlations are not eligibleto predict the result of using nanoparticles and inclination angle in plain tube. Therefore, it is important to introduce a new equation in upward and downward singlephase flow in the inclined plain tubes.

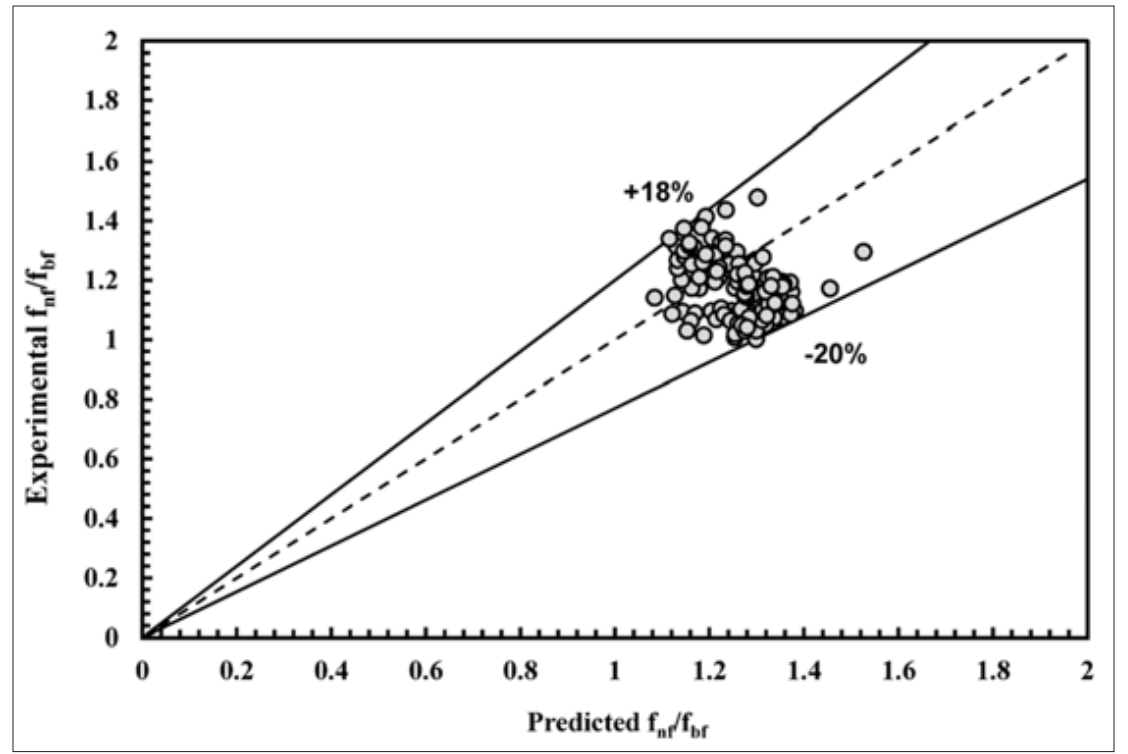

Figure 5: Comparison of the experimental Darcy friction factor of the nanofluid flow with the prediction of Eq. (4) inside inclined plain pipe $(a=270,330300,0,30,60,90)$.

Microfin tube: In order to determine the hydraulic development-length which is extremely effective on the shape of flow and flow regime, hydraulic development-length is acquired from $L \mathrm{e}<0.058 R e \mathrm{~d} d$. The maximum hydraulic development-length calculated to be $0.41 \mathrm{~m}$. The result of Darcy friction factor of copper oxide-thermal oil nanofluid flow in upward and downward flow in inclined microfin tube is plotted in Figure 6. The increment of Graetz number, nanoparticle mass concentration and inclination 
angle can be influential on the growth of Darcy friction factor. The decrease of the boundary layer and the increment of Darcy friction factor are happened because of the creation of the nanoparticle Brownian motion and formation of vortex flow in the inclined microfin tube. Another reason may be the expansion of velocity profile and sharing wall stress. The influence of changing density on the increment of mass concentration and the improvement of heat transfer is accepted. Therefore, the increment of Darcy friction factor is approximately $64 \%$.

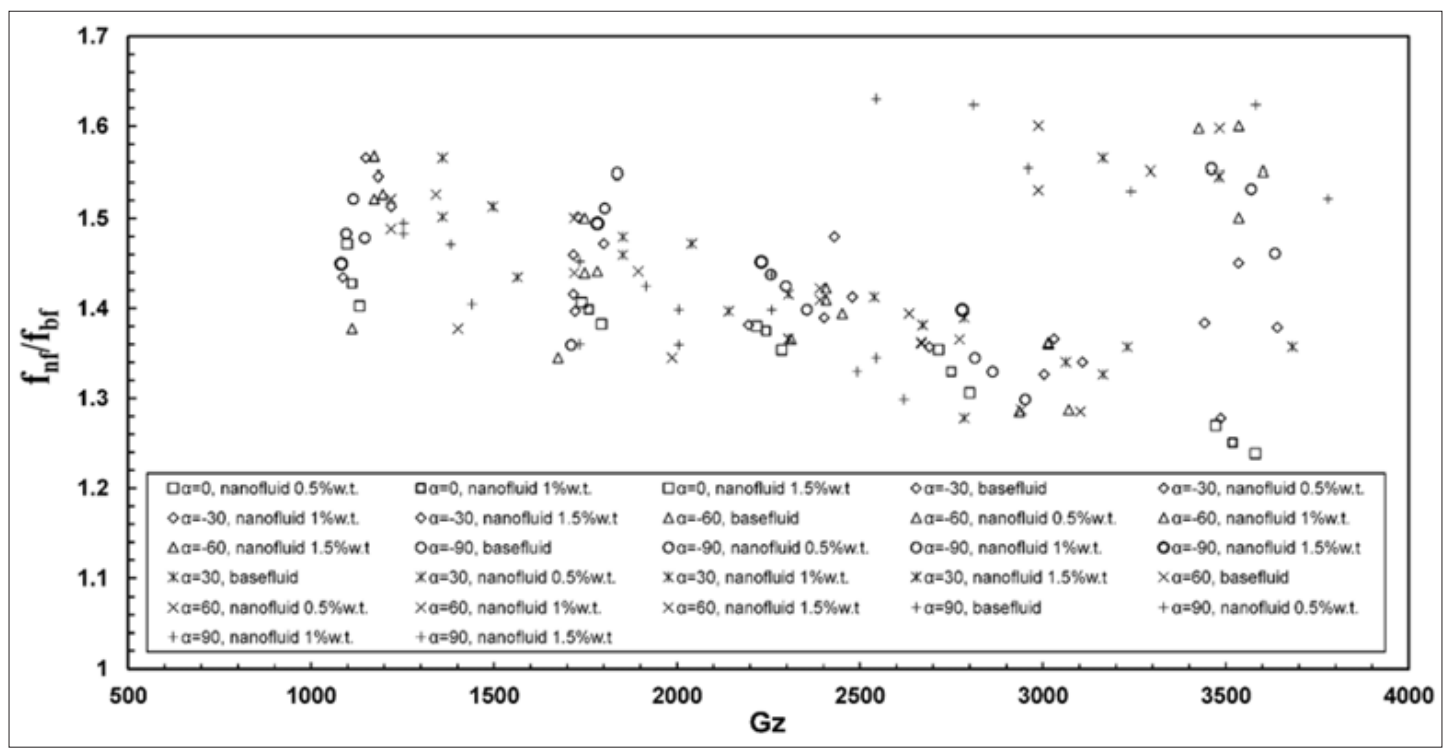

Figure 6: The influence of using $\mathrm{CuO}$ nanoparticles on the Darcy friction factor of the nanofluid flow in the inclined microfin pipes based on the Darcy friction factor $(a=270,330300,0,30,60,90)$.

There is no classical correlation to anticipate the result of Darcy friction factor nanofluid in inclined microfin tube. To predict the influence of using nanofluid and positive inclination angle on Darcy friction factor in microfin tube, a new correlation is introduced based on empirical information and that is acquired from experiments. Indeed, most of the correlations presented are based on Rayleigh number and Richardson number; although, this equation is obtained based on Graetz number. This is because it is popular to use forced convection in industrial usages. The advisable correlation is demonstrated to estimate the friction factor of copper oxide-thermal oil flow in an inclined microfin tube. It is as follows:

$$
\frac{f_{n_{f}}}{f_{b_{f}}}=0.56(1+\cos \theta)^{0.1}(1+\varphi)^{0.5}\left(1+G z^{0.1}\right)^{0.45}\left(\frac{\mu_{n_{f}}}{\mu_{b_{f}}}\right)^{0.14}
$$

The equation evaluates for $0<\varphi<1.5 \%, 0<\theta<90,270<\theta<0$, $200<R e<800,300<P r_{\mathrm{nf}}<402,1080<G z<3600$. The use of positive inclination angle, nanoparticle mass concentration, Reynolds number, dynamic viscosity ratio is acquired by Darcy frictionfactor of copper oxide-thermal oil nanofluid. The comparison between experimental results and predicted results based on Eq. 5 is presented in Figure 5. It is seen that the maximum deflection of experimental results is almost $21 \%$. Thus, the advisable equation can be used for the anticipation of the experimental Darcy friction factor. This is a workable equation because of gaining weight concentration, Graetz number, positive inclination angle, and the dynamic viscosity ratio. The lack of workable classical equations is proven since they do not predict the result of using nanoparticles and inclination angle in microfin tube. Hence, it is weighty tointroduce equations in upward and downward single-phase flow in the inclined microfin tubes.

\section{Heat transfer}

Plain tube: The estimation of thermal development-length of nanofluid should be presented due to the determination of the flow regime and flow shape. The estimation is conducted utilizing thermally development-length $L_{\mathrm{e}}<0.058 R e P r$. The minimum value of thermally development-length is $\mathrm{m}$. Although it is confirmable that the use of nanofluid and plain pipe can be effective on convective heat transfer, the effects of negative inclination angle, nanofluid and plain tube on heat transfer are not determined in prior literature. Figure 5 shows that maximum Nusselt number is obtained into nanoparticle mass concentration $1.5 \%$, the inclination angle of $30^{\circ}$, and Graetz number. The adjustment of angles and nanoparticles Brownian motion can affect flow shape or it can build the vortex flow. This is because the boundary flow decreases in upward and downward single-phase flow in inclined plain pipes. By using empirical data, an equation is introduced to predict the effects of nanofluids, positive inclination angle on convective heat transfer in inclined pipes as follows

$$
N u=0.39(1+\varphi)^{0.1}(1+\operatorname{Cos} \theta)^{0.1}\left(1+(G z P r)^{0.68}\right)^{0.46}\left(\frac{\mu_{n_{f}}}{\mu_{b_{f}}}\right)^{(0.14)}
$$

The correlation evaluates for $0<\varphi<1.5 \%, 0<\theta<90,270<\theta<0$, $200<R e<800,300<P r_{\mathrm{nf}}<405,1100<G z<3800$. The comparison between the empirical results with estimated Eq. (6) is shown in Figure 7. The maximum aberration of the experimental information is almost $20 \%$. The inaccuracy of the correlation is acceptable to be used for the anticipationof convective heat transfer in upward and downward single-phase flow in inclined plain pipes. 


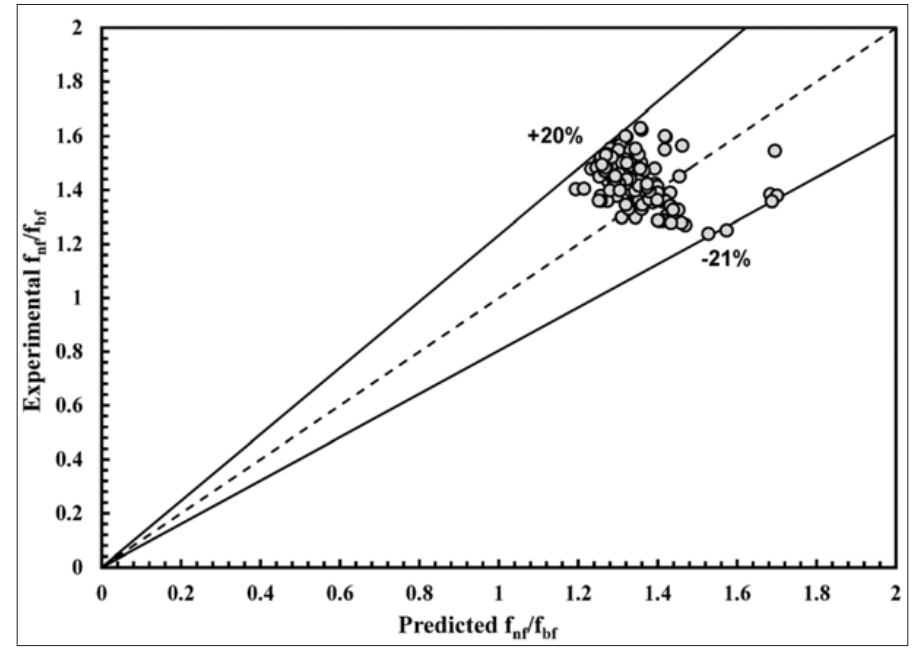

Figure 7: Comparison of the experimental Darcy friction factor of the nanofluid flow with the prediction of Eq. (5) inside inclined microfin pipe ( $a=270,330300,0,30,60,90)$.

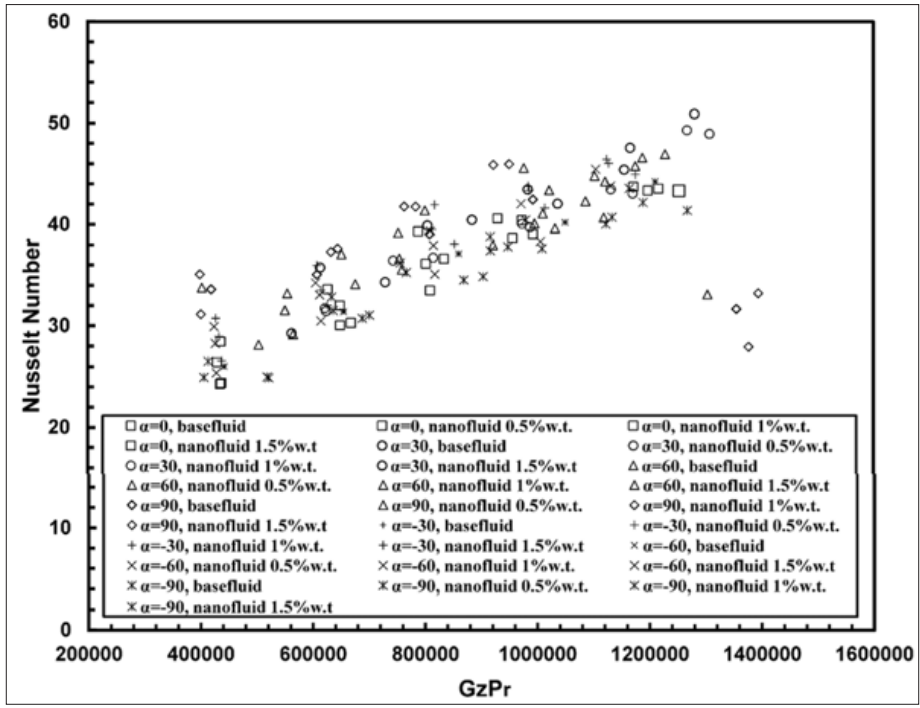

Figure 8: The influence of using $\mathrm{CuO}$ nanoparticles on the Nusselt number of the nanofluid in downward singlephase flow in inclined plain pipes $(a=270,330300,0,30,60,90)$.

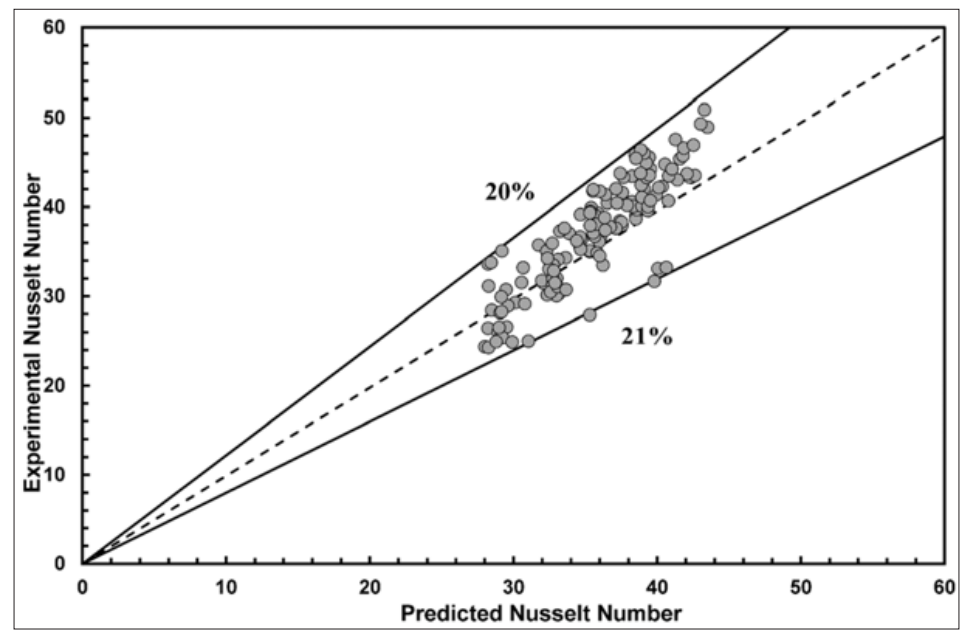

Figure 9: Comparison of the experimental forced convective heat transfer of the nanofluid flow with the prediction of Eq. (6) in inclined plain pipe ( $a=270,330300,0,30,60,90)$. 
Microfin tube: The estimation of thermal development-length of nanofluid should be presented due to the determination of the flow regime and flow shape. The estimation is conducted using thermal development-length $L \mathrm{e}<0.058 R e P r$. The minimum value of thermally development-length is $42 \mathrm{~m}$. The effects of nanofluid, microfin pipe, negative inclination angle on heat transfer is not determined in prior literature. Figure 10 shows that the maximum Nusselt number in nanoparticle mass concentration to be $1.5 \%$, inclination angle of $30^{\circ}$, and Graetz number. The adjustment of angles and nanoparticles Brownian motion can affect flow shape or it can build the vortex flow. It is recognizable by changing the angle of tube and fluid in inclination that the boundary flow will change in upward and downward single-phase flow in the inclined microfin pipes. Using practical data, an equation is offered to show the effects of nanofluids, positive inclination angle on convective heat transfer in inclined pipes. It is as follows:

$$
N u=0.45(1+\varphi)^{0.1}(1+\cos \theta)^{0.1}\left(1+(G Z P r)^{0.05}\right)^{0.46}\left(\frac{\mu_{n_{f}}}{\mu_{u_{f}}}\right)^{(0.14)}
$$

The correlation were obtained for $<\varphi<1.5 \%, \quad 0<\theta<90$, $270<\theta<0, \quad 200<R e<800,300<P r_{\mathrm{nf}}<405,1100<G z<3800$. The comparison between the empirical results and estimated Eq. (7) is shown in Figure 11. The maximum aberration of the experimental information is almost $21 \%$. The inaccuracy of the correlation is acceptable to use for anticipation of convective heat transfer in upward and downward single-phase flow in inclined microfin pipes.

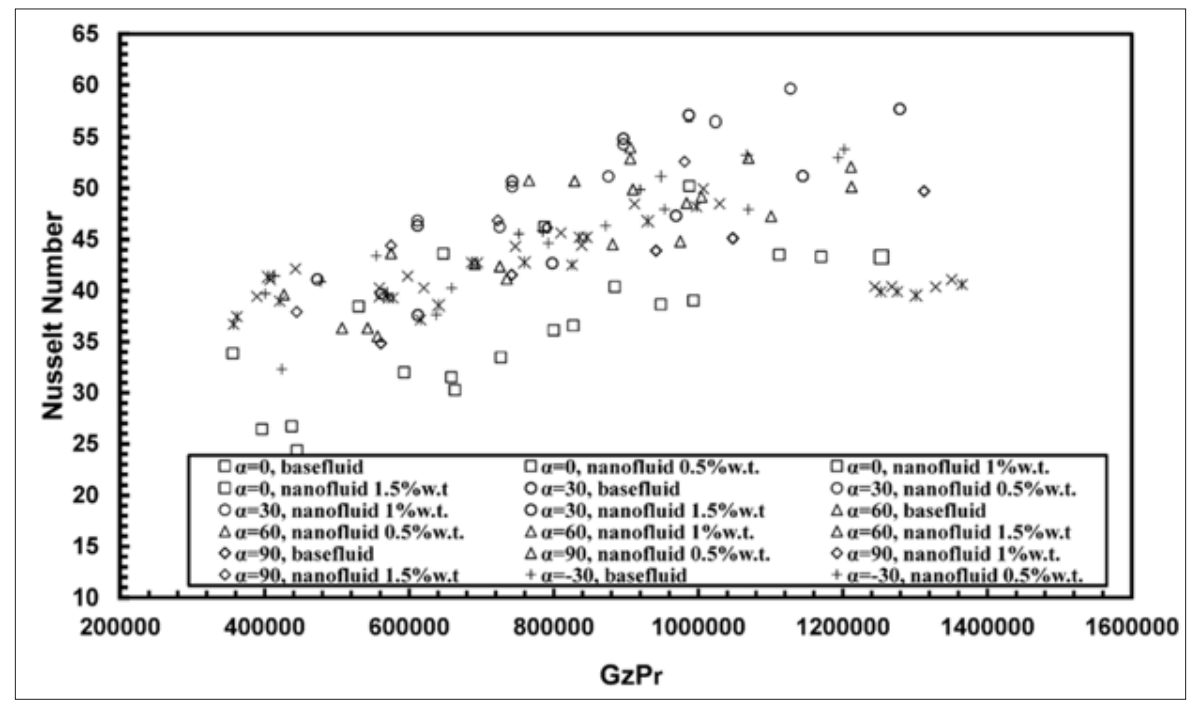

Figure 10: The influence of using $\mathrm{CuO}$ nanoparticles on the Nusselt number of the nanofluid in downward single-phase flow in inclined microfin pipes $(a=270,330300,0,30,60,90)$.

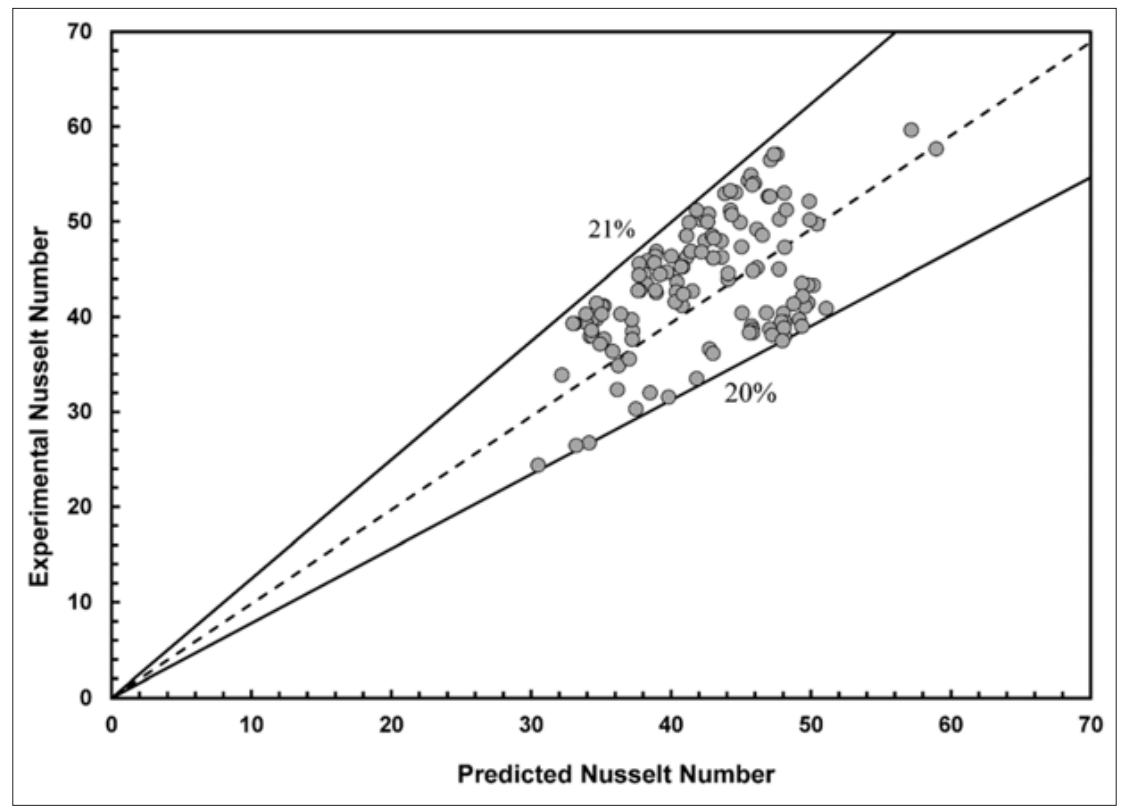

Figure 11: Comparison of the experimental forced convective heat transfer of the nanofluid flow with the prediction of Eq. (7) in inclined plain pipe $(a=270,330300,0,30,60,90)$. 


\section{Figure of merit}

Accompanying convective heat transfer with the boom in pressure drop should be acquireddue to introducing the effects of the augmentation of pressure drop on heat transfer enhancement, the FOM is introduced here $[46,47]$ :

$$
F O M=\frac{h_{n_{f}} / h_{b_{f}}}{\left(\Omega_{n_{f}} / \Omega_{b_{f}}\right)^{(1 / 3)}}
$$

The FOM is introduced to estimate empirical information, which is acceptable to be suggested for industrial uses. The FOM defines the ratio of increasing convective heat transfer with experimental pumping power. The impact of nanofluid and positive inclination angles in inclined plain, finned pipes on convective heat transfer and pressure drop are presented at the same time. If the FOM to be more than a unit, the impact of nanofluids, positive inclination angle, plain and finned pipe will be useful. Figure $12 \& 13$ illustrate the combination of nanofluid, finned tube, and the positive inclination angle, enhance the convective heat transfer in plain and microfin tube about $63 \%$ and $59 \%$, respectively, which can be seen at nanoparticles'mass concentration which is $1.5 \%$ and inclination angles of $300^{\circ}$ and $60^{\circ}$. The FOM in microfin tube is lower than the plain tube since Darcy friction factor and pressure drop in microfin tube are more than the plain tube. Another reason may be the attenuation of nanoparticles' Brownian motion in finned tube. This is because vortex flow, which is created in microfin tube has a significant role in improving convective heat transfer in microfin tube and the reduction of the boundary layer. As a result, the effect of nanofluid on heat transfer attenuates in finned tubes [48].

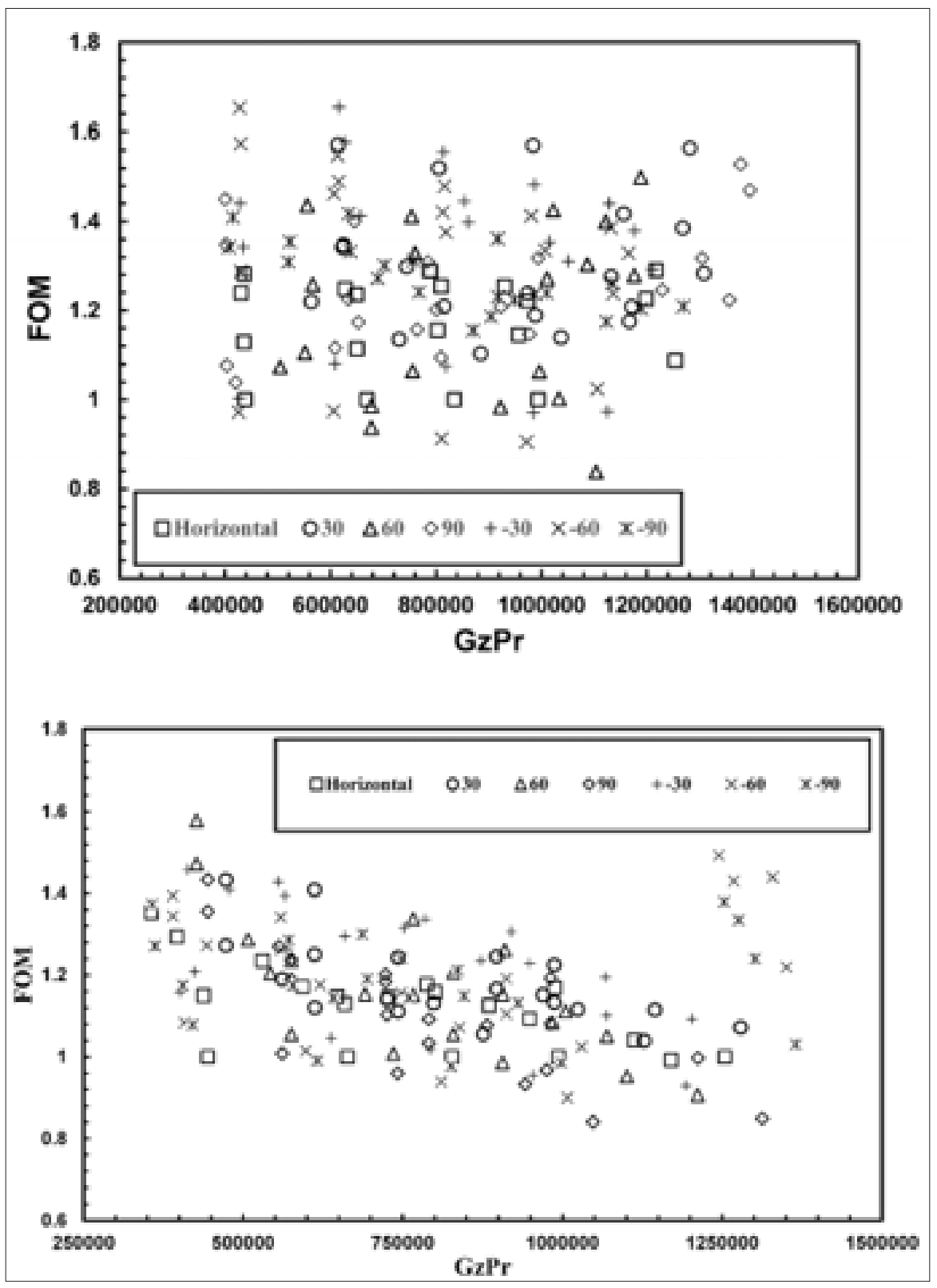

Figure 12: The FOM of HTO-CuO nanofluid flow in inclination tubes based on base fliud in plain tube and Eq. (8): a) plain tube b) microfin tube. 
The adaptation of Darcy friction factor of nanofluid in upward and downward single-phase flow in inclined plain and microfin tube is small. This is due to the anti-friction characteristics of copper oxide. The friction factor declines due to the replacement of the friction mode fromthe sliding mode to the rolling mode. The roller impact has already been defined in the literature [8].

\section{Conclusion}

The influence of copper oxide-thermal oil nanofluid on convective heat transfer and pressure drop in upward and downward single-phase flow in inclined microfin tube is investigated empirically in this article. The limited area of nanoparticle mass concentration and positive inclination angle take values from $0 \%$ to $1.5 \%, 0^{\circ}$ to $90^{\circ}$ and $270^{\circ}$ to $0^{\circ}$, respectively. The result of experimental research in upward and downward single-phase flow in inclined tubes shows that convective heat transfer and pressure drop augment with a surge in the nanoparticles mass concentration of $0 \%$ to $1.5 \%$, Prandtl number of 300 to 405, and Graetz number from 1080 to 3800 . New correlations are introduced to anticipate the influence of nanofluid under constant wall temperature, upward and downward flow on heat transfer and pressure drop in inclined finned tube. The results of the equations are acceptable due to the maximum deflection of experimental results. The maximum deflection is lower than $21 \%$. The augmentation of heattransfer and pressure drop is due to the declination of the boundary layer, the increment of constant velocity and nanoparticle Brownian motion. This will be influential on the forming of vortex and share wall stress. Therefore, the convective heat transfer and pressure drop are increased due to using nanofluid, the downward and upward single-phase flow in inclined plain and microfin tubes.

In order to define the effects of nanofluid and positive inclination angle which are useful in industrial usages, the accompaniment of heat transfer enhancement with the boom in pressuredrop is performed. The results of computation illustrate that utilization of nanofluid, positive inclination angles and microfin tube have positive effects on heat transfer while pressure droprises slightly.

\section{References}

1. Huang L, Farrell KJ (2010) Mixed convection in vertical tube: High reynolds number. Int Heat Transfer Con 2: 269-276.

2. Zeldin B, Schmidt FW (1972) Developing flow with combined forcedfree convection in an isothermal vertical tube. J Heat Transfer 94(2): 211- 221.

3. Laskowski GM, Kearney SP, Evans G, Greif R (2007) Mixed convection heat transfer to and from a horizontal cylinder in cross-flow with heating from below. Int J heat Fluid Flow 28(3): 454-468.

4. Brown AR, Thomas MA (1965) Combined free and forced convection heat transfer for laminar flow in horizontal tubes. J Mech Eng Sci 7(4): 440-448.

5. Pascal J, Greif R (1985) An investigation of laminar mixed convection inside a horizontal tube with isothermal wall conditions. Int J Heat and Mass Transfer 28(7): 1293-1305.

6. Hasadi YM, Busedra AA, Rusturn IM (2007) Laminar mixed convection in the entrance region of horizontal semicircular duct with the flat wall at the top. J Heat Transfer 129(9): 1203-1211.
7. Barozzi GS, Zanchini E, Mariotti M (1985) Experimental investigation of combined forced and free convection in horizontal and inclined tubes. Meccanica 20: 18-27.

8. Choudhury D, Pantakar SV (1989) Combined forced and free laminar convection in the entrance region of an inclined isothermal tube. J Heat Transfer 110(4a): 901-909.

9. Mare T, Voicu I, and Miriei J (2006) Experimental analysis of mixed convection in inclined tube. Appl Thermal Eng 26(14-15): 1677-1683.

10. Naddaf A, Zeinali Heris S (2018) Experimental study on thermal conductivity and electrical conductivity of diesel oil-based nanofluids of graphene nanoparticles and carbon nanotube. Int Commun Heat and Mass Transfer 95: 116-122.

11. Anoop K, Sadr R, Al-Jubouri M, Amani M (2014) Rheology of mineral oil$\mathrm{SiO}_{2}$ nanofluid at high pressure and high temperatures. Int J Thermal Sci 77: 108-115.

12. Papari MM, Yousefi F, Moghadasi J, Karimi H, Campo A (2010) Modeling thermal conductivity augmentation of nanofluids using diffusion neural networks. Int J Thermal Sci 50(1): 44-52.

13. Kariminpour A, Ghasemi S, Hossein M (2018) A new correlation for estimating the thermal conductivity and dynamic viscosity of $\mathrm{CuO} /$ liquid paraffin nanofluid using neural network method. Int Commun Heat and Mass Transfer 92: 90-99.

14. Abroumand S, Jafarimoghaddam A (2018) Tungsten(III) oxide $\left(\mathrm{WO}_{3}\right)$ silver/transformer oil hybrid nanofluid: Preparation, stability, thermal conductivity and dielectric strength. Alex Eng J 57(1): 169-174.

15. Aberoumand S, Jafarimoghaddam A (2017) Experimental study on synthesis, stability, thermal conductivity and viscosity of Cu-engine oil nanofluid. J Taiwan Inst Chem E 71: 315-322.

16. Ilays SU, Pendyala R, Narahari M, Susin L (2017) Stability rheology and thermal analysis of functionalized alumina-thermal oil-based nanofluid for advanced cooling systems. Energy Con Mang 142: 215229.

17. Wang B, Wang X, Lou W, Hao J (2012) Thermal conductivity and rheological properties of graphite/oil nanofluid. Colloids Sur A: Physicoch Eng 414: 125-131.

18. Colangelo G, Favale E, Risi A, Laforgia D (2012) Results of experimental investigations on the heat transfer conductivity of nanofluid based on diathermic oil for high temperature applications. Applied Energy 97: 828-833.

19. Wei B, Zou C, Yuan X, Li X (2017) Thermo-physical properties evaluation of diathermic oil-based hybrid nanofluids for heat transfer applications. Int J Heat Mass Transfer 107: 281-287.

20. Manimaran R, Palaniradja K, Alagumurthi N, Sendhilnathan S, Hussain J (2014) Preparation and characterization of copper oxide nanofluid for heat transfer applications. App Nanosci 4(2): 163-167.

21. Li D, Xie W, Fang W (2011) Preparation and properties of copper-oilbased nanofluid. Nanoscale Res let 6(1): 373.

22. Durga PV, Gupta AV, Deepak K (2015) Investigation of Trapezoidalcut twisted tape insert in a double pipe U-tube heat exchanger using $\mathrm{Al}_{2} \mathrm{O}_{3}$ /water nanofluid. Procedia Mat Sci 10: 50-63.

23. Magesh BD, Nagarajan PK, Madhu B, Ravishankar S (2017) Experimental evaluation of friction factor and heat transfer enhancement of twisted tape inserts using $\mathrm{TiO}_{2}$-water nanofluids. J Eng Therm 26(4): 567-579.

24. Ranjbarzadeh R, Meghdadi AH, Hojaji M (2018) Experimental investigation of heat transfer and friction coefficient of the water/ graphene oxide nanofluid in a pipe containing twisted tape insert under air cross-flow. Exp Heat Transfer 31(5): 373-390.

25. Ashok K, Hanmanthu B (2018) Performance analysis of waterbased copper oxide nanofluid in heat exchanger with twisted insert. Material Sci Eng 330: 19-20. 
26. Mukesh KPC, Kumar J, Tamilarasan R, Sendhil NS, Suresh S (2014) Heat transfer enhancement and pressure drop analysis in a helically coiled tube using $\mathrm{Al}_{2} \mathrm{O}_{3}$ /water nanofluid. J Mech Sci Tech 28(5): 1841-1847.

27. Wu Z, Wang L, Sundèn B (2013) Pressure drops and convective heat transfer of water and nanofluids in a double-pipe helical heat exchanger. Appl Thermal Eng 60(1-2): 266-274.

28. Kazemi MH, Akhavan BMA, Fakoor PM (2013) Pressure drop and heat transfer characteristics of MWCNT/Heat transfer oil nanofluid flow inside micro finned helical tubes with constant wall temperature. Advance Mat Res 622-623: 796-800.

29. Akhavan MA, Hekmatipour F, Mirhabibi SM, Sajadi B (2014) An empirical study on heat transfer and pressure drops properties of heat transfer oil-copper oxide nanofluid in microfin tubes. Int Commun Heat Mass Transfer 57: 150-156.

30. Hekmatipour F, Jalali M, Hekmatipour F, Akhavan MA, Sajadi B (2018) On the convection heat transfer and pressure drop of copper oxide-heat transfer oil nanofluid in inclined microfine pipe. Heat Mass Transfer.

31. Jafarimoghaddam A, Aberoumand S, Javaherdeh K, Abbasian Arani AA, Jafarimoghaddam R (2018) Al/oil nanofluid inside annular tube: an experimental study on convective heat transfer and pressure drop. Heat Mass Transfer 54(4): 1053-1106.

32. Jafarimoghaddam A, Aberoumand S (2018) On the evaluation of a finned annular tube in convective heat transfer performance in the presence of Ag/oil nanofluid for a constant thermal flux rate boundary condition. Heat Transfer Asian Res.

33. Akhavan-Behabadi MA, Hekmatipour F, Sajadi B (2016) An experimental study on the mixed convection transfer and pressure drop of HTO/CuO nanofluid in inclined tubes. Exp Thermal Fluid Sci 78: 10-17.

34. Ben Mansour R, Galanis N, Nguyen CT (2011) Experimental study of mixed convection with water-Al2 03 nanofluid in inclined tube with uniform wall heat flux. Int J Thermal Sci 50(3): 403-410.

35. Akbari M, Behzadmehr A, Shahraki F (2008) Fully developed mixed convection in horizontal and inclined tubes with uniform heat flux using nanofluid. Int J Heat Fluid Flow 29(2): 545-556.

36. Hekmatipour F, Akhavan-Behabadi MA, Sajadi B, Fakoor-Pakdaman M (2017) Mixed convection heat transfer and pressure drop characteristics of the copper oxide-heat transfer oil (CuO-HTO) nanofluid in vertical tube. Case studies Thermal Eng 10: 532-540.
37. Allahyari Sh, Ghaderi A, Behzadmehr A, Fallah K, Nasimi MH, Hassani $M$ (2016) Investigating the effects of nanoparticles mean diameter on laminar mixed convection of a nanofluid through an inclined tube with circumferentially nonuniform heat flux. J Eng Thermophysics 25(4): 563-575.

38. Hekmatipour F, Jalali M (2019) Application of copper oxide-thermal oil (CuO-HTO) nanofluidon convective heat transfer enhancement in inclined circular tube. J Thermal Anal Calorimetry 136: 2449-2459.

39. Hekmatipour F, Jalali M (2020) Heat transfer and pressure drop of copper oxide-thermal oil in upward single-phase flow in inclined microfin tube under constant wall temperature. J Thermal Anal Calorimetry 139: 2203-2214.

40. Akhavan-Behabadi MA, Hekmatipour F, Mirhabibi SM, Sajadi B (2015) Experimental investigation of thermal-rheological properties and heat transfer behaviour of the heat transfer oil-copper oxide (HTO-CuO) nanofluid in smooth tubes. Experimental Thermal and Fluid Sciences 68: 681-688.

41. Moffat RJ (1988) Describing the uncertainties in experimental result. Experimental Thermal Fluid Science 1(1): 3-17.

42. Lorenzini M, Morini GL, Henning T, Brandnet J (2008) Uncertainty assessment in friction factor measurements as a tool to design experimental set-ups. International Journal of Thermal Science 48(2): 282-289.

43. Rohsenow WM, Hartnett JP, Cho YI (1998) Handbook of Heat transfer, ( $3^{\text {rd }}$ edn), McGraw-Hill, New York, USA.

44. Holman JP (2010) Heat Transfer, (10 $0^{\text {th }}$ edn), McGraw Hill, New York, USA.

45. Hashemi SM, Akhavan-Behabadi MA (2012) An empirical study on heat transfer and pressure drop characteristics of $\mathrm{CuO}$-based oil nanofluid flow in a horizontal helically coiled tube under constant heat flux. Int Commun Heat Mass Transfer 39(1): 144-151.

46. Ho CJ, Chen WC, Yan WM (2013) Experimental study on cooling performance of minichannel heat sink using water-based MEPCM particle. Int commun Heat Mass Transfer 48: 67-72.

47. Routbort JL, Singh D, Timofeeva EV, France DM (2011) Pumping power of nanofluid in flowing system. J Nanopart Res 13: 931-937.

48. Akhavan-Behabadi MA, Ghazvini M, Rasoli E (2010) Experimental investigation on heat transfer and pressure drop of nanodimondengine oil nanofluid in microfin tube. 14 International Heat Transfer Conference, Washington, DC, USA.

For possible submissions Click below: 